\title{
A SuRVey of Public OpINION ABOUt CONNECTED VEHICLES IN THE U.S., THE U.K., AND AUSTRALIA
}

\section{BRANDON SCHOETTLE MiCHAEL SiVAK}

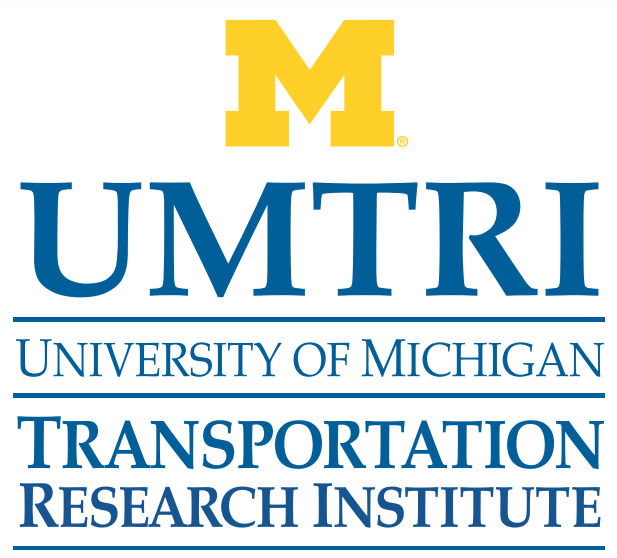




\title{
A SURVEY OF PUBLIC OPINION ABOUT CONNECTED VEHICLES IN
}

\section{THE U.S., THE U.K., AND AUSTRALIA}

\author{
Brandon Schoettle \\ Michael Sivak
}

The University of Michigan

Transportation Research Institute

Ann Arbor, Michigan 48109-2150

U.S.A.

Report No. UMTRI-2014-10

April 2014 
Technical Report Documentation Page

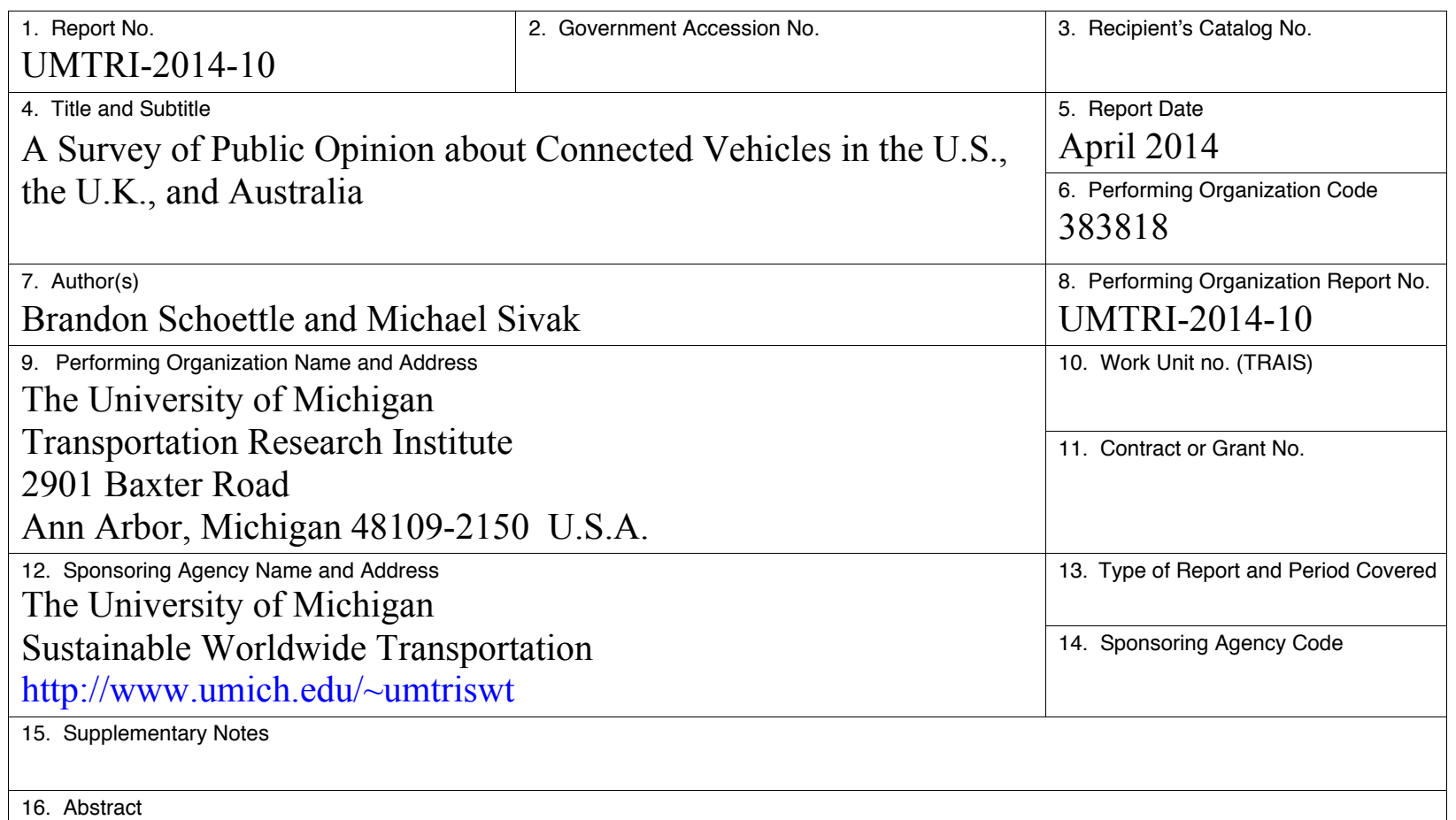

This survey examined public opinion regarding connected-vehicle technology across three major English-speaking countries - the U.S., the U.K., and Australia. The survey yielded useable responses from 1,596 persons over the age of 18 .

The main results were as follows:

- The majority of respondents had not previously heard of connected-vehicle technology; however, most had a positive initial opinion of the technology.

- The majority felt that the expected benefits presented in the survey are likely to occur.

- Respondents generally expressed a high level of concern regarding the security and performance issues presented in the survey.

- The majority of those surveyed stated that safety was the most important aspect of connected vehicles.

- Most individuals said that it is important for personal communication devices to integrate with connected vehicles, as well as for such vehicles to have Internet connectivity.

- The majority of respondents expressed a desire to have this technology in their vehicle.

- Willingness to pay for connected-vehicle technology was very similar across the three countries.

The main implications of these results are that the general public in the three countries surveyed feel positive about connected vehicles, have optimistic expectations of the benefits (while still maintaining some concerns), and generally desire connected-vehicle technology when it becomes available.

\begin{tabular}{|c|c|c|c|}
\hline $\begin{array}{l}\text { 17. Key Words } \\
\text { connected vehicles, survey } \\
\text { V2V }\end{array}$ & U.S., U.K., Australia, publi & opinion, & $\begin{array}{l}\text { 18. Distribution Statement } \\
\text { Unlimited }\end{array}$ \\
\hline $\begin{array}{l}\text { 19. Security Classification (of this report) } \\
\text { None }\end{array}$ & $\begin{array}{l}\text { 20. Security Classification (of this page) } \\
\text { None }\end{array}$ & $\begin{array}{l}\text { 21. No. of Pages } \\
27\end{array}$ & 22. Price \\
\hline
\end{tabular}




\section{Contents}

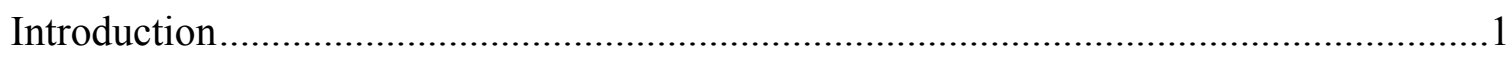

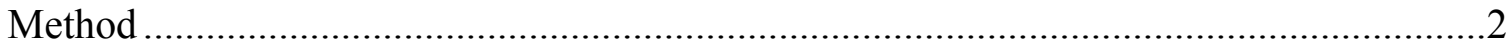

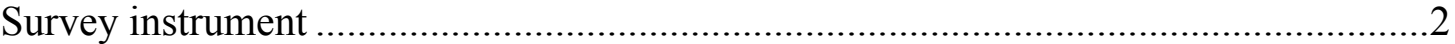

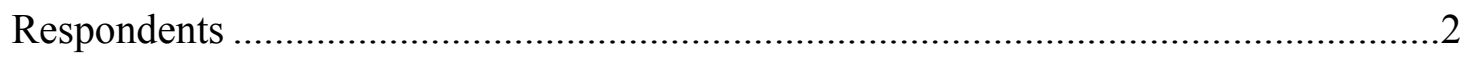

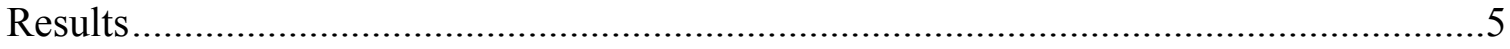

Familiarity with and general opinion about connected vehicles ................................5

Expected benefits of connected vehicles...............................................................

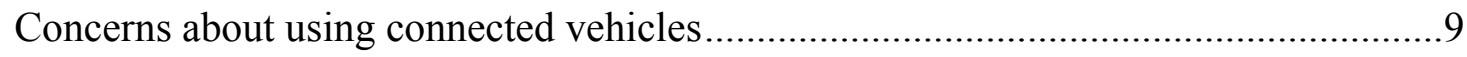

Importance of various connected-vehicle features...............................................11

Overall interest in owning and willingness to pay for connected-vehicle technology .14

Statistically significant demographic effects ....................................................... 15

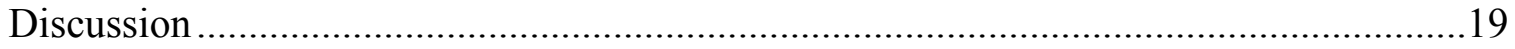

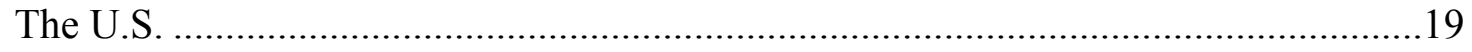

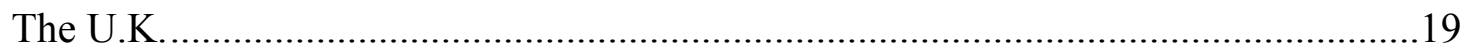

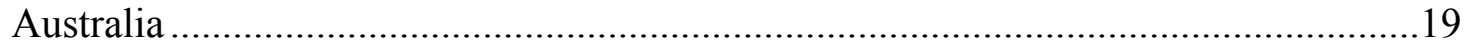

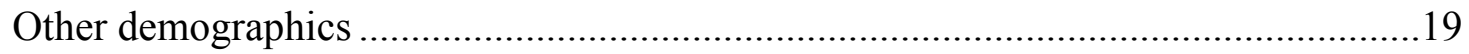

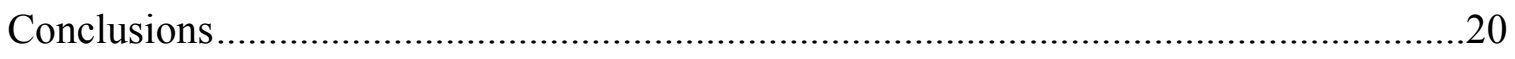

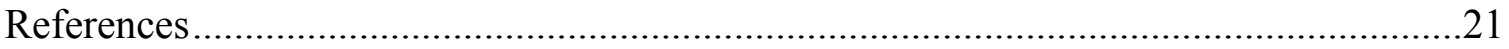

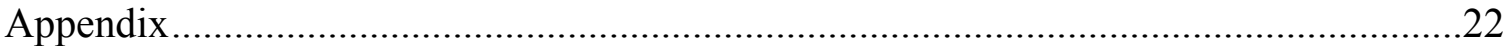




\section{Introduction}

The U.S. Department of Transportation recently announced plans to support the introduction of vehicle-to-vehicle (V2V) communication among light-duty vehicles in the U.S., commonly know as "connected vehicles" (NHTSA, 2014). A pilot study is currently underway at UMTRI to examine the feasibility of V2V communication in a large scale, real-world environment (NHTSA, 2012b). Previous demonstrations of this new technology in driver clinics and focus groups have been perceived favorably by the general public (NHTSA, 2012a). Participants in these clinics, who have observed and used connected-vehicle technology, were largely accepting of it and expressed a desire to have this technology in their vehicles (74\% said they "strongly agree" with the statement that they would like to have V2V safety features on their personal vehicle).

However, for gaining a better understanding of opinions, concerns, and general acceptance by average drivers around the world, these clinics have been limited in terms of their focus, geographic location (six U.S. cities), and number of respondents. Furthermore, while these previous surveys of driver opinion have examined the topic indepth with knowledgeable drivers (i.e., those who have had instruction and were able to drive connected vehicles), less is known about more naïve drivers (i.e., those with little or no prior exposure to connected-vehicle technology or concepts) and/or drivers outside the U.S.

The purpose of this survey was to expand upon the existing data to include a broader examination of public opinion about connected vehicles, especially for drivers unfamiliar with the technology. Additionally, this survey also seeks to expand the geographic coverage to include drivers in countries outside the U.S. To this end, drivers were also surveyed in two other major countries where English is the primary languagethe U.K. and Australia. 


\section{Method}

\section{Survey instrument}

An online survey was conducted using SurveyMonkey (www.surveymonkey.com), a web-based survey company. A questionnaire was developed to examine several key topics related to connected vehicles. The main topics addressed were as follows:

- Familiarity with and general opinion about connected vehicles

- Expected benefits of connected vehicles

- Concerns about using connected vehicles

- Importance of various connected-vehicle features

- Overall interest in owning and willingness to pay for connected-vehicle technology

The same core survey was conducted in each country. However, customized versions of the survey were presented in each country to account for minor differences in spelling (American versus British and Australian) and currency symbols (U.S. and Australian \$ versus British $£)$.

Information related to each respondent's current driver's license status, current vehicle type, and additional demographic information was also collected for inclusion in the analysis. The full text of the questionnaire is included in the appendix. The survey was performed in March 2014.

\section{Respondents}

SurveyMonkey's Audience tool was used to target and recruit individuals over the age of 18 from SurveyMonkey's respondent databases in the U.S., the U.K., and Australia. The recruitment resulted in 1,717 replies from potential respondents. Fully completed surveys were received for 1,596 respondents. The total numbers of completed surveys by country were 576 for the U.S., 520 for the U.K., and 500 for Australia. (These respondents are generally representative of each country's population [SurveyMonkey, 2014]; however, online surveys, by their nature, result in the exclusion of individuals without Internet access.)

The final response rate (i.e., total completed divided by total eligible, or $1,596 / 1,717$ ) was $93 \%$. Demographic breakdowns for the respondents are presented in 
Table 1. (The total in this table and the tables to follow are based on equal weighting of each country.) As is evident in Table 1, the samples for each country were very similar demographically, with only a few notable differences:

- The driver-licensing rate was lower in the U.K. than in the other two countries.

- The full-time employment rate was lower in Australia.

- More minivans, vans, MPVs, pickup trucks, and SUVs were driven in the U.S.

- More individuals in the U.K. reported not driving

- Australians were more likely to report driving motorcycles or scooters. 
Table 1

Demographic breakdown for the final 1,596 respondents.

\begin{tabular}{|c|c|c|c|c|c|}
\hline \multirow{2}{*}{\multicolumn{2}{|c|}{ Demographic aspect }} & \multicolumn{4}{|c|}{ Percent } \\
\hline & & \multirow{2}{*}{$\begin{array}{c}\begin{array}{c}\text { U.S. } \\
(\mathrm{N}=576)\end{array} \\
20.5\end{array}$} & \multirow{2}{*}{$\begin{array}{c}\begin{array}{c}\text { U.K. } \\
(\mathrm{N}=520)\end{array} \\
23.7\end{array}$} & \multirow{2}{*}{$\begin{array}{c}\begin{array}{c}\text { Australia } \\
(\mathrm{N}=500)\end{array} \\
23.6\end{array}$} & \multirow{2}{*}{$\begin{array}{c}\begin{array}{c}\text { Total } \\
(N=1,596)\end{array} \\
22.6\end{array}$} \\
\hline \multirow{6}{*}{ Age group } & 18 to 29 & & & & \\
\hline & 30 to 39 & 21.5 & 21.2 & 23.6 & 22.1 \\
\hline & 40 to 49 & 20.4 & 25.4 & 21.2 & 22.3 \\
\hline & 50 to 59 & 25.3 & 22.5 & 24.4 & 24.1 \\
\hline & 60 to 69 & 12.3 & 7.1 & 6.8 & 8.7 \\
\hline & 70 or older & 0.0 & 0.2 & 0.4 & 0.2 \\
\hline \multirow{2}{*}{ Gender } & Female & 54.2 & 55.2 & 52.6 & 54.0 \\
\hline & Male & 45.8 & 44.8 & 47.4 & 46.0 \\
\hline \multirow{3}{*}{ Education } & Less than bachelor degree & 53.1 & 56.2 & 52.4 & 53.9 \\
\hline & Bachelor degree & 28.3 & 27.7 & 29.4 & 28.5 \\
\hline & Graduate degree & 18.6 & 16.2 & 18.2 & 17.7 \\
\hline \multirow{6}{*}{ Employment } & Employed full-time & 49.1 & 50.4 & 39.2 & 46.2 \\
\hline & Employed part-time & 13.7 & 17.9 & 21.2 & 17.6 \\
\hline & Not currently employed & 19.6 & 16.7 & 20.4 & 18.9 \\
\hline & Retired & 11.3 & 6.9 & 9.8 & 9.3 \\
\hline & Full-time student & 4.5 & 8.1 & 8.0 & 6.9 \\
\hline & Part-time student & 1.7 & 0.0 & 1.4 & 1.0 \\
\hline \multirow{2}{*}{$\begin{array}{l}\text { Currently } \\
\text { licensed? }\end{array}$} & Yes (including suspended) & 91.7 & 82.9 & 90.0 & 88.2 \\
\hline & No & 8.3 & 17.1 & 10.0 & 11.8 \\
\hline \multirow{7}{*}{$\begin{array}{l}\text { Vehicle type } \\
\text { driven most } \\
\text { often }\end{array}$} & Passenger car & 53.8 & 69.6 & 72.2 & 65.2 \\
\hline & Minivan / van / MPV & 10.4 & 4.8 & 3.6 & 6.3 \\
\hline & Pickup truck & 9.2 & 0.6 & 3.0 & 4.3 \\
\hline & SUV & 17.9 & 3.1 & 8.2 & 9.7 \\
\hline & Motorcycle / scooter & 0.3 & 0.4 & 2.0 & 0.9 \\
\hline & Bicycle & 1.9 & 3.5 & 2.8 & 2.7 \\
\hline & Do not drive & 6.4 & 18.1 & 8.2 & 10.9 \\
\hline
\end{tabular}




\section{Results}

\section{Familiarity with and general opinion about connected vehicles}

The majority of respondents in all three countries had not heard of connect vehicles before the survey (Figure 1). The U.S. had the highest percentage responding that they had previously heard of connected vehicles $(26.9 \%)$, followed by Australia $(21.6 \%)$ and the U.K. (17.1\%).

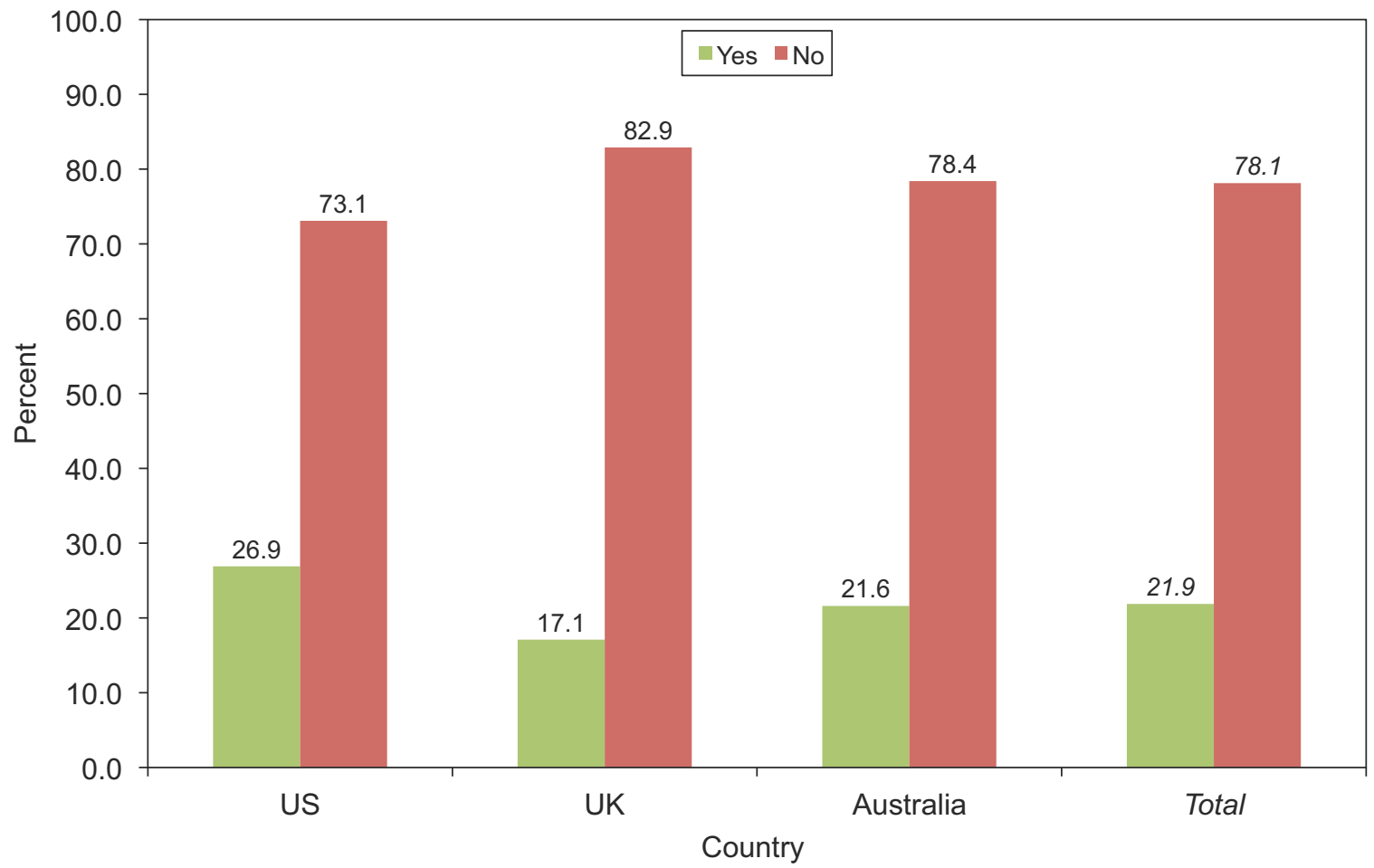

Figure 1. Summary of responses, by country, to Q1: "Had you ever heard of connected vehicles before participating in this survey?"

Most respondents had a positive impression of the technology, with the most positive responses coming from the U.K. (66.6\%), followed by Australia (64.4\%) and the U.S. (56.9\%). Table 2 presents a complete summary of responses by country, while Figure 2 presents collapsed summaries (positive versus negative). Only a small percentage of respondents had any negative impressions, with the highest incidence in the U.S. (6.6\%), followed by the U.K. and Australia (both 4.0\%). Approximately one-third of respondents in each country had a neutral opinion of connected vehicles. 
Table 2

Percentage of responses, by country, to Q2:

"What is your general opinion regarding connected vehicles?"

(The most frequent response is shown in bold.)

\begin{tabular}{|l|r|r|r|r|}
\hline \multicolumn{1}{|c|}{ Response } & U.S. & U.K. & Australia & Total \\
\hline \hline Very positive & 22.0 & 23.3 & 25.2 & 23.4 \\
\hline Somewhat positive & 34.9 & $\mathbf{4 3 . 3}$ & $\mathbf{3 9 . 2}$ & $\mathbf{3 9 . 0}$ \\
\hline Neutral & $\mathbf{3 6 . 5}$ & 29.4 & 31.6 & 32.6 \\
\hline Somewhat negative & 5.0 & 3.8 & 2.8 & 3.9 \\
\hline Very Negative & 1.6 & 0.2 & 1.2 & 1.0 \\
\hline
\end{tabular}

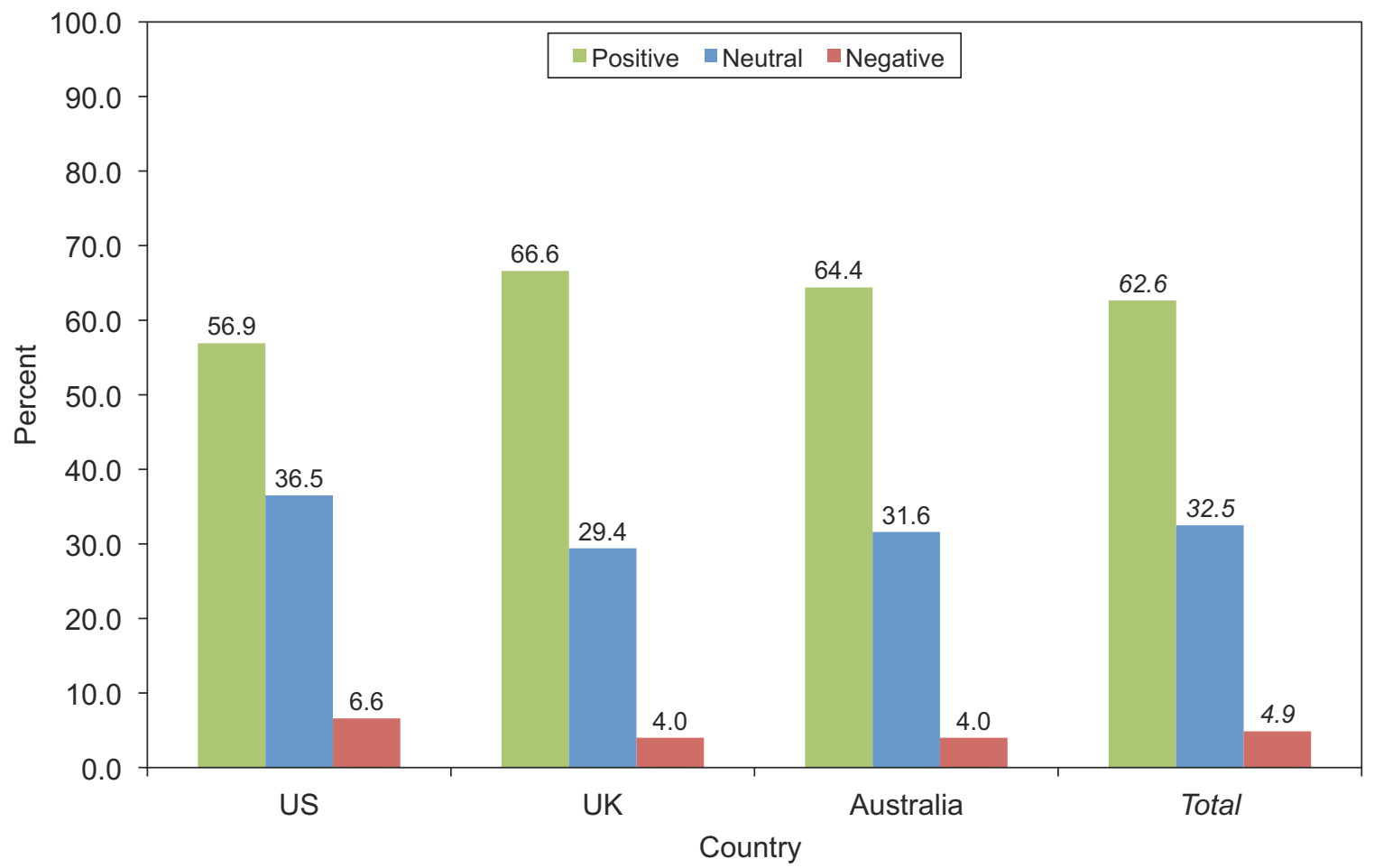

Figure 2. Summary of responses (collapsed), by country, to Q2: "What is your general opinion regarding connected vehicles?" 


\section{Expected benefits of connected vehicles}

Respondents were asked: "How likely do you think it is that the following benefits will occur when using connected vehicles?" They were asked to select "very likely," "somewhat likely," "somewhat unlikely," or "very unlikely" for each item in a list of expected benefits for connected vehicles. Table 3 presents a complete summary of responses by country, while Figure 3 presents collapsed summaries (likely versus unlikely). "Somewhat likely" was the most frequent response for all items in all three countries. The majority of respondents felt that each of the expected benefits was likely to occur with connected vehicles. They were most confident about fewer crashes occurring (when collapsed, 85.9\% said this was "likely"), while they were least confident about reducing driver distractions (61.2\% said this was "likely"). 
Table 3

Percentage of responses, by country, to Q3: "How likely do you think it is that the following benefits will occur when using connected vehicles?"

(The most frequent response is shown in bold.)

\begin{tabular}{|c|c|c|c|c|c|}
\hline Expected benefit & Response & U.S. & U.K. & Australia & Total \\
\hline \multirow{4}{*}{ Fewer crashes } & Very likely & 30.9 & 26.7 & 26.4 & 28.0 \\
\hline & Somewhat likely & 55.0 & 59.4 & 59.4 & 57.9 \\
\hline & Somewhat unlikely & 11.3 & 12.7 & 13.0 & 12.3 \\
\hline & Very unlikely & 2.8 & 1.2 & 1.2 & 1.7 \\
\hline \multirow{4}{*}{ Reduced severity of crashes } & Very likely & 27.6 & 24.6 & 26.8 & 26.3 \\
\hline & Somewhat likely & 54.5 & $\mathbf{5 8 . 8}$ & 58.8 & 57.4 \\
\hline & Somewhat unlikely & 15.1 & 14.8 & 12.8 & 14.2 \\
\hline & Very unlikely & 2.8 & 1.7 & 1.6 & 2.0 \\
\hline \multirow{4}{*}{$\begin{array}{l}\text { Improved emergency response } \\
\text { to crashes }\end{array}$} & Very likely & 31.9 & 27.1 & 30.4 & 29.8 \\
\hline & Somewhat likely & 51.0 & 53.3 & 55.6 & 53.3 \\
\hline & Somewhat unlikely & 14.4 & 18.1 & 11.6 & 14.7 \\
\hline & Very unlikely & 2.6 & 1.5 & 2.4 & 2.2 \\
\hline \multirow{4}{*}{ Less traffic congestion } & Very likely & 19.3 & 16.9 & 21.6 & 19.3 \\
\hline & Somewhat likely & 44.4 & 47.9 & 49.4 & 47.2 \\
\hline & Somewhat unlikely & 29.9 & 30.8 & 25.4 & 28.7 \\
\hline & Very unlikely & 6.4 & 4.4 & 3.6 & 4.8 \\
\hline \multirow{4}{*}{ Shorter travel time } & Very likely & 16.1 & 13.3 & 18.2 & 15.9 \\
\hline & Somewhat likely & 43.9 & 44.0 & 50.0 & 46.0 \\
\hline & Somewhat unlikely & 33.9 & 37.7 & 26.6 & 32.7 \\
\hline & Very unlikely & 6.1 & 5.0 & 5.2 & 5.4 \\
\hline \multirow{4}{*}{ Lower vehicle emissions } & Very likely & 17.4 & 14.8 & 18.2 & 16.8 \\
\hline & Somewhat likely & 47.0 & 48.3 & 51.8 & 49.0 \\
\hline & Somewhat unlikely & 28.1 & 32.7 & 24.2 & 28.3 \\
\hline & Very unlikely & 7.5 & 4.2 & 5.8 & 5.8 \\
\hline \multirow{4}{*}{ Better fuel economy } & Very likely & 23.4 & 16.0 & 21.2 & 20.2 \\
\hline & Somewhat likely & 48.1 & 53.1 & 52.8 & 51.3 \\
\hline & Somewhat unlikely & 22.2 & 28.5 & 21.8 & 24.2 \\
\hline & Very unlikely & 6.3 & 2.5 & 4.2 & 4.3 \\
\hline \multirow{4}{*}{ Lower insurance rates } & Very likely & 22.2 & 16.5 & 18.6 & 19.1 \\
\hline & Somewhat likely & 49.5 & 47.7 & 47.6 & 48.3 \\
\hline & Somewhat unlikely & 21.2 & 27.7 & 26.2 & 25.0 \\
\hline & Very unlikely & 7.1 & 8.1 & 7.6 & 7.6 \\
\hline \multirow{4}{*}{ Fewer distractions for drivers } & Very likely & 17.2 & 13.3 & 19.6 & 16.7 \\
\hline & Somewhat likely & 45.7 & 43.3 & 44.4 & 44.5 \\
\hline & Somewhat unlikely & 27.8 & 33.3 & 27.4 & 29.5 \\
\hline & Very unlikely & 9.4 & 10.2 & 8.6 & 9.4 \\
\hline
\end{tabular}




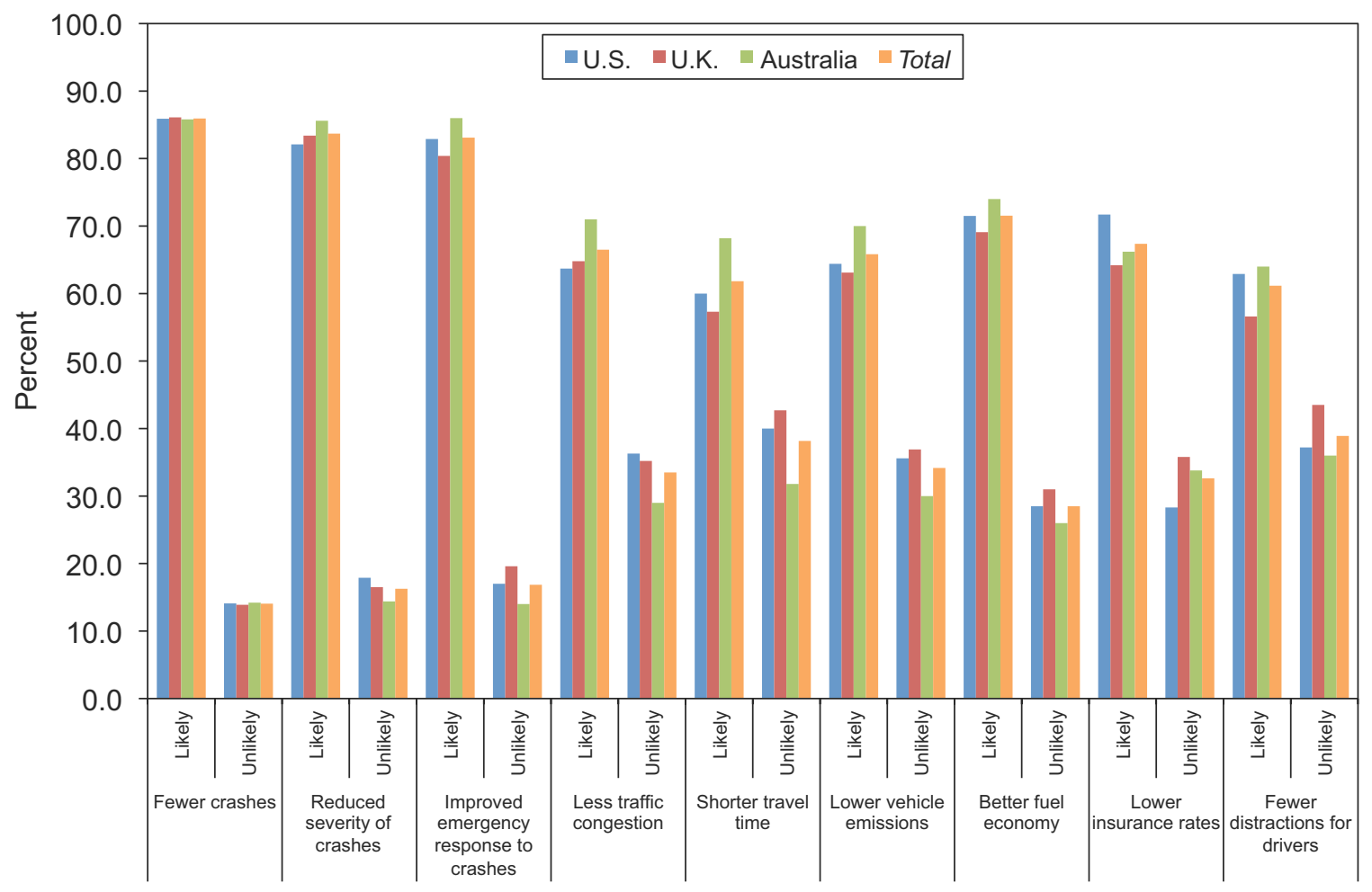

Figure 3. Summary of responses (collapsed), by country, to Q3: "How likely do you think it is that the following benefits will occur when using connected vehicles?"

\section{Concerns about using connected vehicles}

Respondents were asked: "How concerned are you about the following issues related to connected vehicles?" They were asked to select "very concerned," "moderately concerned," "slightly concerned," or "not at all concerned for each item in a list of possible concerns regarding connected vehicles. Table 4 presents a complete summary of responses by country. "Moderately concerned" was the most frequent response for all items in all three countries, except for the following items, about which respondents in the U.S. were most likely to say they were "very concerned":

- System security (from hackers) and vehicle security (from hackers)

- Data privacy (location and speed tracking)

- Drivers relying too much on the technology 
Table 4

Percentage of responses, by country, to Q4: "How concerned are you about the following issues related to connected vehicles?"

(The most frequent response is shown in bold.)

\begin{tabular}{|c|c|c|c|c|c|}
\hline Possible concern & Response & U.S. & U.K. & Australia & Total \\
\hline \multirow{4}{*}{$\begin{array}{l}\text { Safety consequences of } \\
\text { equipment failure or system } \\
\text { failure }\end{array}$} & Very concerned & 33.0 & 26.2 & 27.4 & 28.9 \\
\hline & Moderately concerned & 42.4 & 43.3 & 44.0 & 43.2 \\
\hline & Slightly concerned & 18.9 & 23.1 & 21.2 & 21.1 \\
\hline & Not at all concerned & 5.7 & 7.5 & 7.4 & 6.9 \\
\hline \multirow{4}{*}{$\begin{array}{l}\text { Legal liability for } \\
\text { drivers/owners }\end{array}$} & Very concerned & 26.6 & 20.2 & 24.2 & 23.7 \\
\hline & Moderately concerned & 43.1 & 45.8 & 43.8 & 44.2 \\
\hline & Slightly concerned & 23.4 & 23.3 & 22.8 & 23.2 \\
\hline & Not at all concerned & 6.9 & 10.8 & 9.2 & 9.0 \\
\hline \multirow{4}{*}{$\begin{array}{l}\text { System security (from } \\
\text { hackers) }\end{array}$} & Very concerned & 36.5 & 24.8 & 28.4 & 29.9 \\
\hline & Moderately concerned & 35.1 & 39.0 & 37.6 & 37.2 \\
\hline & Slightly concerned & 22.0 & 25.0 & 23.8 & 23.6 \\
\hline & Not at all concerned & 6.4 & 11.2 & 10.2 & 9.3 \\
\hline \multirow{4}{*}{$\begin{array}{l}\text { Vehicle security (from } \\
\text { hackers) }\end{array}$} & Very concerned & 35.4 & 24.6 & 28.2 & 29.4 \\
\hline & Moderately concerned & 35.2 & 40.8 & 36.8 & 37.6 \\
\hline & Slightly concerned & 22.7 & 24.6 & 24.4 & 23.9 \\
\hline & Not at all concerned & 6.6 & 10.0 & 10.6 & 9.1 \\
\hline \multirow{4}{*}{$\begin{array}{l}\text { Data privacy (location and } \\
\text { speed tracking) }\end{array}$} & Very concerned & 37.7 & 29.0 & 28.8 & 31.8 \\
\hline & Moderately concerned & 35.2 & 39.8 & 37.6 & 37.5 \\
\hline & Slightly concerned & 20.7 & 21.0 & 24.6 & 22.1 \\
\hline & Not at all concerned & 6.4 & 10.2 & 9.0 & 8.5 \\
\hline \multirow{4}{*}{$\begin{array}{l}\text { Interacting with non- } \\
\text { connected vehicles }\end{array}$} & Very concerned & 21.5 & 17.3 & 20.8 & 19.9 \\
\hline & Moderately concerned & 40.1 & 37.9 & 40.6 & 39.5 \\
\hline & Slightly concerned & 25.9 & 30.0 & 26.8 & 27.6 \\
\hline & Not at all concerned & 12.5 & 14.8 & 11.8 & 13.0 \\
\hline \multirow{4}{*}{$\begin{array}{l}\text { Interacting with pedestrians } \\
\text { and bicyclists }\end{array}$} & Very concerned & 24.5 & 18.8 & 24.4 & 22.6 \\
\hline & Moderately concerned & 40.1 & 39.8 & 39.2 & 39.7 \\
\hline & Slightly concerned & 24.5 & 26.9 & 23.4 & 24.9 \\
\hline & Not at all concerned & 10.9 & 14.4 & 13.0 & 12.8 \\
\hline \multirow{4}{*}{$\begin{array}{l}\text { Learning to use connected } \\
\text { vehicles }\end{array}$} & Very concerned & 22.4 & 16.2 & 19.2 & 19.3 \\
\hline & Moderately concerned & 40.1 & 40.2 & 39.0 & 39.8 \\
\hline & Slightly concerned & 24.5 & 26.7 & 26.8 & 26.0 \\
\hline & Not at all concerned & 13.0 & 16.9 & 15.0 & 15.0 \\
\hline \multirow{4}{*}{$\begin{array}{l}\text { Increased distractions for } \\
\text { drivers }\end{array}$} & Very concerned & 27.8 & 21.7 & 27.8 & 25.8 \\
\hline & Moderately concerned & 41.7 & 41.5 & 38.6 & 40.6 \\
\hline & Slightly concerned & 22.2 & 28.7 & 24.2 & 25.0 \\
\hline & Not at all concerned & 8.3 & 8.1 & 9.4 & 8.6 \\
\hline \multirow{4}{*}{$\begin{array}{l}\text { System performance in poor } \\
\text { weather? }\end{array}$} & Very concerned & 28.5 & 16.5 & 20.6 & 21.9 \\
\hline & Moderately concerned & 39.6 & 38.8 & 39.6 & 39.3 \\
\hline & Slightly concerned & 23.4 & 29.6 & 29.4 & 27.5 \\
\hline & Not at all concerned & 8.5 & 15.0 & 10.4 & 11.3 \\
\hline \multirow{4}{*}{$\begin{array}{l}\text { Drivers will rely too much } \\
\text { on the technology? }\end{array}$} & Very concerned & 41.7 & 36.2 & 36.0 & 38.0 \\
\hline & Moderately concerned & 35.8 & 39.0 & 38.0 & 37.6 \\
\hline & Slightly concerned & 16.1 & 18.3 & 18.4 & 17.6 \\
\hline & Not at all concerned & 6.4 & 6.5 & 7.6 & 6.8 \\
\hline
\end{tabular}




\section{Importance of various connected-vehicle features}

The vast majority of respondents in all three countries said that "safety" was the most important aspect of connected-vehicle technology (83.8\% overall; Figure 4$)$. The U.K. had the highest percentage responding that safety was most important $(85.4 \%)$, followed by the U.S. (83.9\%) and Australia (82.0\%). "Mobility" was ranked as second most important (10.4\% overall), followed by "environment" (5.9\% overall).

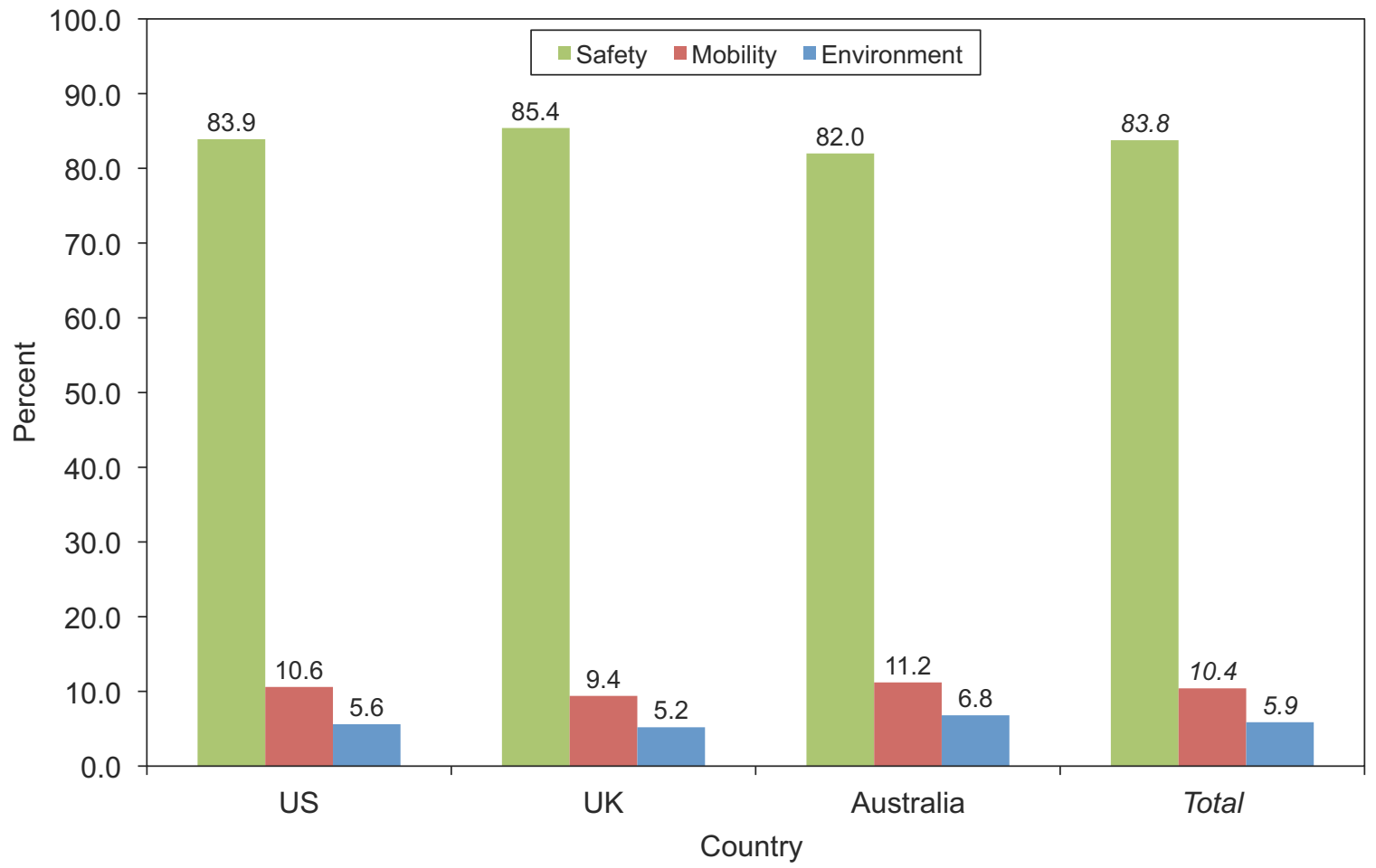

Figure 4. Summary of responses, by country, to Q5: "Of the three main areas that connected vehicles are expected to encompass-safety, mobility and the environmentwhich is most important to you?" 
The importance of connected vehicles being able to integrate with personal communication devices was rated similarly across all three countries, with most respondents assigning some level of importance to this feature. (Overall only 21.2\% said "not at all important"; Figure 5.) Respondents in the U.S. were the most likely to say that integrating with personal communication devices was important (only 18.9\% said "not at all important"), followed by the U.K. (22.3\%) and Australia (22.4\%). "Moderately important" was the most frequent response in all three countries (34.1\% overall).

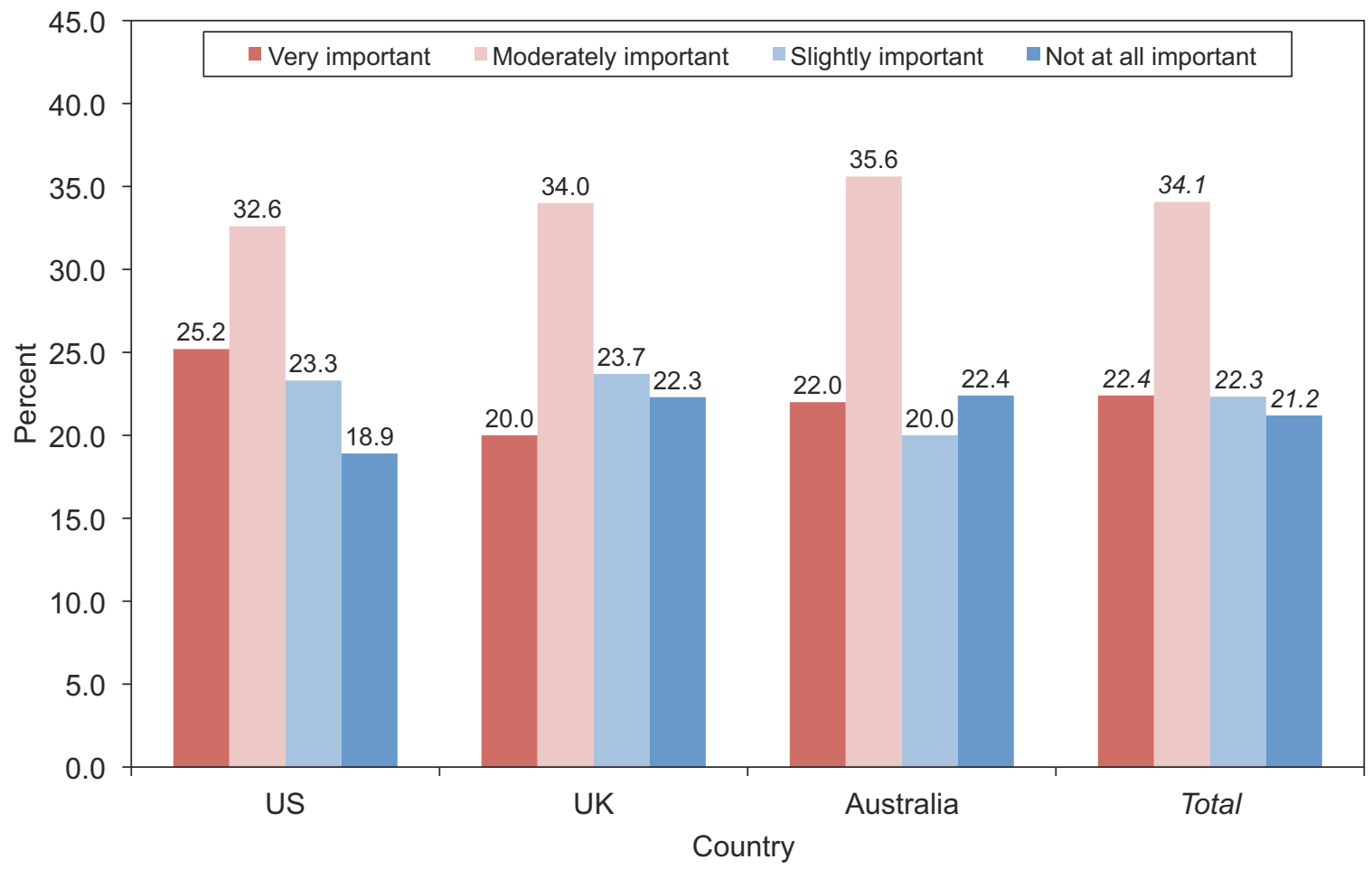

Figure 5. Summary of responses, by country, to Q8: "How important is it to you that connected-vehicle technologies are able to integrate with your personal communication device(s)?" 
The importance of Internet connectivity in connected vehicles was also rated similarly across all three countries, with most respondents assigning some level of importance to this feature. (Overall only $23.1 \%$ said "not at all important"; Figure 6.) Respondents in the U.S. were the most likely to say that Internet connectivity was important (only $21.7 \%$ said "not at all important"), followed by the U.K. (23.5\%) and Australia (24.0\%). "Moderately important" was the most frequent response in all three countries (31.1\% overall).

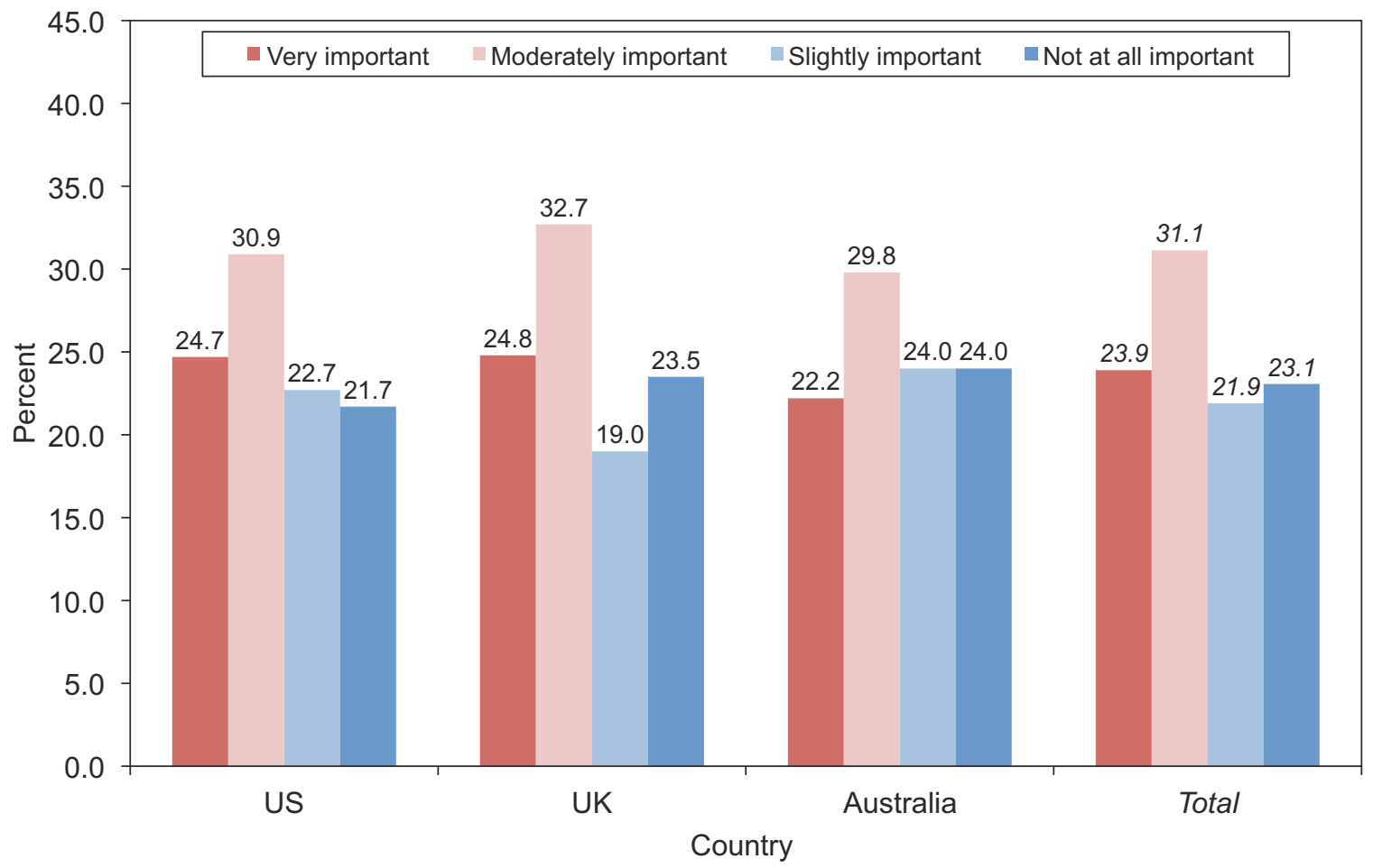

Figure 6. Summary of responses, by country, to Q9: "How important is it to you that connected-vehicle technologies include Internet connectivity?" 


\section{Overall interest in owning and willingness to pay for connected-vehicle technology}

Overall interest in having connected-vehicle technology was similar across all three countries, with most respondents expressing some level of interest in having the technology. (Overall only 14.3\% said, "not at all interested"; Figure 7.) Respondents in the U.K. and Australia were tied for being most likely to say they were interested in this technology (only 14.2\% said "not at all important" for both countries), followed by the U.S. (14.6\%). "Moderately interested" was the most frequent response in all three countries $(38.0 \%$ overall).

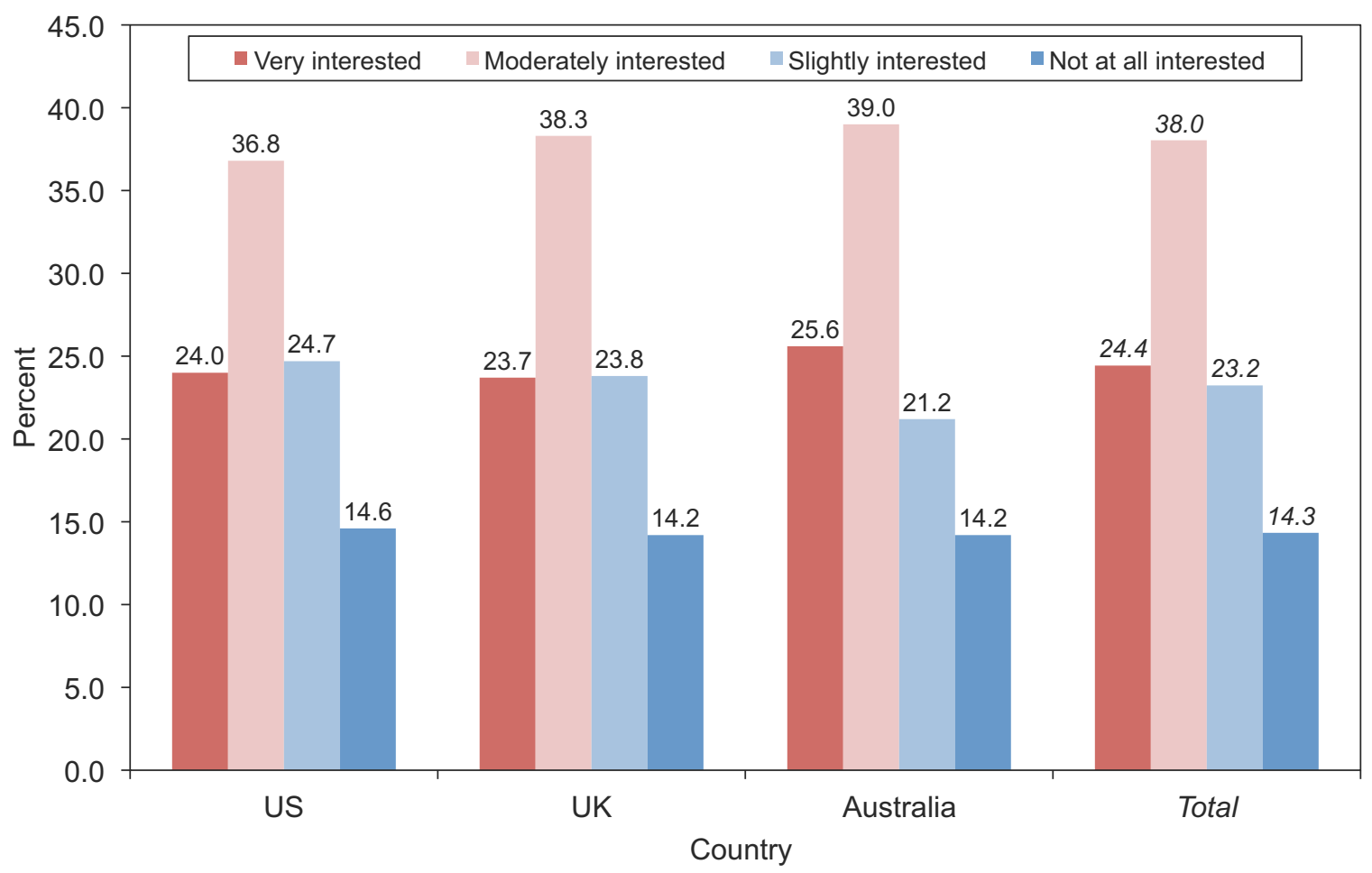

Figure 7. Summary of responses, by country, to Q6: "How interested would you be in having this technology on a vehicle you drive?" 
Results showing how much extra individuals would be willing to pay to have connected-vehicle technology are presented in Table 5. (Respondents were asked to input an amount in their local currency; these amounts were recalculated to US\$ using current currency-conversion rates.)

In the U.S., $25 \%$ of respondents $\left(75^{\text {th }}\right.$ percentile) were willing to pay at least $\$ 500$ for this technology. The corresponding amounts in the Australia and the U.K. were $\$ 455$ and \$394, respectively. However, a sizeable proportion of respondents said they would not be willing to pay extra for this technology (a response of $\$ 0$ was given by $45.5 \%$ in the U.S., $44.8 \%$ in the U.K., and $42.6 \%$ in Australia).

Table 5

Summary, by country, for Q7: "How much extra would you be willing to pay to have this technology on a vehicle you drive?" (Responses were given in the local currency; amounts in this table were recalculated to US\$ using current currency conversion rates.)

\begin{tabular}{|l|r|r|r|r|}
\hline \multicolumn{1}{|c|}{ Measure } & \multicolumn{1}{c|}{ U.S. } & \multicolumn{1}{c|}{ U.K. } & Australia & \multicolumn{1}{c|}{ Total } \\
\hline \hline $10^{\text {th }}$ percentile & $\$ 0$ & $\$ 0$ & $\$ 0$ & $\$ 0$ \\
\hline $25^{\text {th }}$ percentile & $\$ 0$ & $\$ 0$ & $\$ 0$ & $\$ 0$ \\
\hline $50^{\text {th }}$ percentile (median) & $\$ 20$ & $\$ 33$ & $\$ 46$ & $\$ 44$ \\
\hline $75^{\text {th }}$ percentile & $\$ 500$ & $\$ 394$ & $\$ 455$ & $\$ 455$ \\
\hline $90^{\text {th }}$ percentile & $\$ 1,500$ & $\$ 996$ & $\$ 910$ & $\$ 1,000$ \\
\hline Percent responding $\$ 0$ & $45.5 \%$ & $44.8 \%$ & $42.6 \%$ & $44.4 \%$ \\
\hline
\end{tabular}

\section{Statistically significant demographic effects}

For each question in the survey, the responses for each individual demographic variable or grouping were compared using one-way analysis of variance (ANOVA). Table 6 presents a summary matrix from the series of ANOVAs, indicating statistically significant effects of demographic groupings on individual questions, either at $p \leq .05$, $p \leq .01$, or $p \leq .001$. The statistically significant results at the $p \leq .001$ level are discussed below. 
Table 6

Summary matrix from a series of one-way ANOVAs indicating statistically significant effects of demographic groupings (columns) on responses to individual questions (rows).

\begin{tabular}{|c|c|c|c|c|c|c|c|c|c|}
\hline \multirow[b]{2}{*}{ Question } & \multicolumn{9}{|c|}{ Demographic variable or group } \\
\hline & $\begin{array}{c}\text { Q1 } \\
\text { Ever } \\
\text { heard of }\end{array}$ & $\begin{array}{c}\text { Q2 } \\
\text { Initial } \\
\text { opinion }\end{array}$ & $\begin{array}{c}\text { Q10 } \\
\text { Gender }\end{array}$ & $\begin{array}{l}\text { Q11 } \\
\text { Age }\end{array}$ & $\begin{array}{c}\text { Q12 } \\
\text { Education }\end{array}$ & $\begin{array}{c}\text { Q13 } \\
\text { Employment } \\
\text { status }\end{array}$ & $\begin{array}{c}\text { Q14 } \\
\text { License } \\
\text { status }\end{array}$ & $\begin{array}{c}\text { Q15 } \\
\text { Vehicle } \\
\text { type }\end{array}$ & Country \\
\hline Q3 a & $* * *$ & $* * *$ & & * & & * & & & \\
\hline Q3_b & $* *$ & $* * *$ & & & & & & $*$ & \\
\hline Q3_c & $* * *$ & $* * *$ & & & & $* *$ & & $*$ & \\
\hline Q3_d & & $* * *$ & & & & & & & $*$ \\
\hline Q3_e & & $* * *$ & & & & & & & $* *$ \\
\hline Q3_f & & $* * *$ & & $*$ & & & & & \\
\hline Q3_g & & $* * *$ & & & & & & & \\
\hline Q3_h & $* * *$ & $* * *$ & & $*$ & & & & $*$ & $*$ \\
\hline Q3_i & & $* * *$ & & & & & & & $*$ \\
\hline Q4_a & & $* * *$ & $*$ & & $* * *$ & & $* *$ & $* *$ & $*$ \\
\hline Q4_b & & $* * *$ & & & $* *$ & & $* * *$ & $*$ & $*$ \\
\hline Q4_c & & $* * *$ & $*$ & & & $*$ & & & $* * *$ \\
\hline Q4_d & & $* * *$ & & & & & & & $* * *$ \\
\hline Q4_e & & $* * *$ & & & & $*$ & $*$ & & $* *$ \\
\hline Q4_f & & & & & & & & $*$ & $*$ \\
\hline Q4 _g & & $*$ & & & $*$ & * & & & $*$ \\
\hline Q4_h & & & $* * *$ & & & & & $*$ & $*$ \\
\hline Q4_i & & $* *$ & & & $* * *$ & & * & $* * *$ & \\
\hline $\mathrm{Q} 4$ j & & $* *$ & & & & & & & $* * *$ \\
\hline Q4_k & & $* * *$ & & & & & $* * *$ & & \\
\hline Q5 & & $* * *$ & $* *$ & $*$ & & $* *$ & $* * *$ & $* *$ & \\
\hline Q6 & $* * *$ & $* * *$ & $* *$ & $* * *$ & $* * *$ & $* * *$ & $* *$ & $* * *$ & \\
\hline Q7 & $* * *$ & $* * *$ & & & $* *$ & $* *$ & & & \\
\hline Q8 & $* * *$ & $* * *$ & & $* * *$ & $* * *$ & $* * *$ & & $* *$ & \\
\hline Q9 & $* * *$ & $* * *$ & & $* * *$ & $* * *$ & $* * *$ & & & \\
\hline
\end{tabular}

$*=p \leq .05$

$* *=p \leq .01$

$* * *=p \leq .001$ 
Ever heard of connected vehicles (Q1). Respondents who had previously heard of connected vehicles were more likely to expect crash-reduction benefits and lower insurance rates. These respondents were also more interested in having the technology on their vehicle, and were more likely to say that integration with personal communication devices and Internet connectivity were important features of connected vehicles. Those having previously heard of connected vehicles would be willing to pay more for the technology than those who had not, and were less likely to say they would not pay anything extra.

Initial opinion of connected vehicles (Q2). Predictably, a respondent's initial opinion of connected vehicles had a significant effect on nearly every response. As such, we will not examine these results in detail.

Gender (Q10). Females were more likely to express concern about learning to use connected-vehicle technology.

Age (Q11). Younger respondents had a greater general interest in having connected-vehicle technology, and were more likely to rate integration with personal communication devices and Internet connectivity in the vehicle as being important.

Education (Q12). Higher education levels were associated with greater general interest in having connected-vehicle technology, and greater likelihood of rating integration with personal communication devices and Internet connectivity in the vehicle as being important.

Employment status (Q13). For respondents who were employed full time, and for students of any type, there was a greater general interest in having connected-vehicle technology. These respondents also had a greater likelihood of rating integration with personal communication devices and Internet connectivity in the vehicle as being important.

Driver's license status (Q14). Individuals without a driver's license were more likely to feel that the environmental aspects of connected vehicles are most important, and less likely to feel that the safety aspects are most important.

Vehicle type (Q15). There was a significant effect of vehicle type on a respondent's general interest in having connected-vehicle technology. Motorcycle and scooter drivers were more likely to express an interest in connected-vehicle technology 
(compared with all other groups). Conversely, bicycle riders and those who do not drive any vehicle were less likely to express an interest in having this technology.

Country. Respondents in the U.S. expressed greater concern regarding system security (from hackers), vehicle security (from hackers), data privacy (location and speed tracking), and system performance in poor weather.

Country also had a highly significant effect $(p<.001)$ on the distribution of responses to two of the grouping variables used in the analysis: Ever heard of connected vehicles and Initial opinion of connected vehicles. Respondents in the U.K. were significantly less likely to have previously heard of connected vehicles, and U.S. respondents had a significantly less positive initial opinion of connected vehicles. 


\section{Discussion}

The results from all three countries surveyed were remarkably similar in most regards. However, some subtle but noteworthy differences between the countries do exist.

\section{The U.S.}

Respondents in the U.S. had less positive initial opinions of connected vehicles. U.S. respondents were more likely than their foreign counterparts to say they were "very concerned" about system security (from hackers), vehicle security (from hackers), data privacy (location and speed tracking), and system performance in poor weather.

\section{The U.K.}

Respondents in the U.K. showed the lowest initial familiarity with the concept of connected vehicles, yet started the survey with the most positive opinions about the technology. Individuals in the U.K were also more likely to not have a driver's license and to not drive a vehicle of any kind. U.K. respondents were less concerned with security related to hacking and data privacy than U.S. respondents.

\section{Australia}

Australians generally indicated more optimistic expectations for benefits from mobility applications. Like their U.K. counterparts, Australian respondents were less concerned with security related to hacking and data privacy than U.S. respondents.

\section{Other demographics}

In general, having previously heard of connected vehicles and a respondent's initial opinion of the technology were the strongest predictors of overall opinions regarding connected vehicles. Prior knowledge of connected vehicles and a positive initial opinion were both associated with positive overall opinions and expectations of the technology. 


\section{Conclusions}

This survey examined public opinion regarding connected-vehicle technology across three major English-speaking countries - the U.S., the U.K., and Australia. The survey yielded useable responses from 1,596 persons over the age of 18 .

The results were generally very uniform across the three countries surveyed. The main findings share a high level of agreement for the following aspects:

- The majority of respondents had not previously heard of connected-vehicle technology; however, most had a positive initial opinion of the technology.

- The majority felt that the expected benefits presented in the survey are likely to occur, especially for the crash reduction and mitigation benefits of connected vehicles.

- Respondents generally expressed a high level of concern regarding the security and performance issues presented in the survey.

- The majority of those surveyed stated that safety was the most important aspect of connected vehicles (versus mobility or environment).

- Most individuals felt that it is important for personal communication devices to integrate with connected vehicles, as well as for such vehicles to have Internet connectivity.

- The majority of respondents expressed a desire to have this technology in their vehicle.

- The willingness to pay for connected-vehicle technology was similar across the three countries; although just under half of the respondents in each country were unwilling to pay extra for the technology, those who were willing to pay offered similar amounts in each country.

The main implications of these results are that the general public in the three countries surveyed feel positive about connected vehicles, have optimistic expectations of the benefits (while still maintaining some concerns), and generally desire connectedvehicle technology when it becomes available. 


\section{References}

NHTSA [National Highway Traffic Safety Administration]. (2012a). Light vehicle driver acceptance clinics. Preliminary results. Available at: http://www.safercar.gov/staticfiles/safercar/connected/Driver_Acceptance_Clinics Results.pdf

NHTSA [National Highway Traffic Safety Administration]. (2012b). Questions \& answers about DOT's safety pilot "model deployment". Available at: http://www.safercar.gov/staticfiles/safercar/connected/Technical_Fact_SheetModel_Deployment.pdf

NHTSA [National Highway Traffic Safety Administration]. (2014). U.S. Department of Transportation announces decision to move forward with vehicle-to-vehicle communication technology for light vehicles. Available at: http://www.nhtsa.gov/About+NHTSA/Press+Releases/2014/USDOT+to+Move+For ward + with + Vehicle-to-Vehicle+Communication + Technology + for + Light + Vehicles

SurveyMonkey. (2014). Is my SurveyMonkey Audience sample representative? Available at: http://help.surveymonkey.com/articles/en_US/kb/Is-mySurveyMonkey-Audience-sample-representative.

U.S. DOT [U.S. Department of Transportation]. (2014). Connected vehicle research. Connected vehicle frequently asked questions. Available at: http://www.its.dot.gov/connected vehicle/connected vehicles_FAQs.htm 


\section{Appendix}

\section{Opinions Concerning Connected Vehicles Survey (via SurveyMonkey)}

We are conducting a survey of opinions about connected vehicles.

An explanation of what is meant by connected vehicles will be shown on the next page. Please take a moment to read that description of connected-vehicle technology carefully before continuing with the survey.

Connected-vehicle technologies are envisioned to ultimately encompass safety, mobility, and environmental applications.

Connected-vehicle safety applications would enable vehicles to have 360-degree awareness to inform a vehicle operator of hazards and situations they cannot see. These safety applications have the potential to reduce crashes through advisories and warnings. For instance, vehicle operators may be advised of a school zone, sharp curve, or slippery patch of roadway ahead, and may be warned in more imminent crash situations, such as during merging operations or if the vehicle ahead stops suddenly. Vehicles can also be warned of bicycles and pedestrians through connected-vehicle technology, enhancing the safety of these travel modes.

Connected-vehicle mobility applications are intended to provide a connected, data-rich travel environment based on information transmitted anonymously from thousands of vehicles that are using the transportation system at a particular time. This information could help transportation managers monitor and manage transportation system performance by adjusting traffic signals, transit operations, or dispatching maintenance crews or emergency services, for example.

Providing travelers with real-time information about traffic congestion and other travel conditions is expected to help them make more informed decisions that can reduce the environmental impact of their trip. Informed travelers may decide to avoid congestion by taking alternate routes or public transit, or by rescheduling their trip, all of which can make their trip more fuel-efficient and ecofriendly. The ability for vehicles to "talk to" the infrastructure could provide information to the vehicle operator so that he/she can drive through a traffic signal network at optimum speeds to reduce stopping.

1) Had you ever heard of connected vehicles before participating in this survey? Yes

No 
2) What is your general opinion regarding connected vehicles?

Even if you had never heard of connected vehicles before participating in this survey, please give us your opinion based on the description you just read.

Very positive

Somewhat positive

Neutral

Somewhat negative

Very negative

3) How likely do you think it is that the following benefits will occur when using connected vehicles?

Please select one response per row.

$$
\text { Very likely } \begin{gathered}
\text { Somewhat } \\
\text { likely }
\end{gathered} \quad \begin{gathered}
\text { Somewhat } \\
\text { unlikely }
\end{gathered} \quad \begin{gathered}
\text { Very } \\
\text { unlikely }
\end{gathered}
$$
a. Fewer crashes
b. Reduced severity of crashes
c. Improved emergency response to crashes
d. Less traffic congestion
e. Shorter travel time
f. Lower vehicle emissions
g. Better fuel economy
h. Lower insurance rates
i. Fewer distractions for drivers

4) How concerned are you about the following issues related to connected vehicles?

Please select one response per row.

Very Moderately Slightly Not at all concerned concerned concerned concerned

a. Safety consequences of equipment failure or system failure

b. Legal liability for drivers/owners

c. System security (from hackers)

d. Vehicle security (from hackers)

e. Data privacy (location and speed tracking)

f. Interacting with non-connected vehicles

g. Interacting with pedestrians and bicyclists

h. Learning to use connected vehicles

i. Increased distractions for drivers

j. System performance in poor weather

$\mathrm{k}$. Drivers will rely too much on the technology 
5) Of the three main areas that connected vehicles are expected to encompass - safety, mobility and the environment-which is most important to you?

Safety

Mobility

Environment

6) How interested would you be in having this technology on a vehicle you drive?

Very interested

Moderately interested

Slightly interested

Not at all interested

7) How much extra would you be willing to pay to have this technology on a vehicle you drive? (Please enter 0 if you would not be willing to pay extra for this technology.) [Respondents were asked to input an amount in their local currency; these amounts were recalculated to US\$ using current currency conversion rates.]

8) How important is it to you that connected-vehicle technologies are able to integrate with your personal communication device(s)?

Very important

Moderately important

Slightly important

Not at all important

9) How important is it to you that connected-vehicle technologies include Internet connectivity?

Very important

Moderately important

Slightly important

Not at all important

10) Now we would like to know some basic background information about you.

What is your gender?

Female

Male 
11) What is your age?

18 to 24

25 to 29

30 to 34

35 to 39

40 to 44

45 to 49

50 to 54

55 to 59

60 to 64

65 to 69

70 or older

12) What is the highest level of education you have completed?

Less than bachelor degree

Bachelor degree

Graduate degree

13) What is your current level of employment?

Please select only ONE option that best describes you.

Employed full-time

Employed part-time

Not currently employed

Retired

Full-time student

Part-time student

14) Do you currently have a valid driver's license?

[UK: "driving licence"; Australia: "driver's licence"]

Yes (including a suspended license) [UK/Australia: "licence"]

No

15) What kind of vehicle do you drive most often?

Passenger car (any type or size)

Minivan / van / MPV (multipurpose vehicle)

Pickup truck

SUV (sport utility vehicle)

Motorcycle / scooter

Bicycle

Do not drive 